\title{
Two-Center Experience in the Endovascular Treatment of Ruptured and Unruptured Intracranial Aneurysms Using the WEB Device: A Retrospective Analysis
}

\author{
(D). Popielski, (D) A. Berlis, (DW. Weber, and (D) S. Fischer
}

\begin{abstract}
BACKGROUND AND PURPOSE: The safety and efficacy of the Woven EndoBridge (WEB) device for the treatment of cerebral aneurysms has been investigated in several studies. Our objective was to report the experience of 2 neurovascular centers with the WEB device in the treatment of broad-based intracranial aneurysms, including the technical feasibility and safety as well as short- and midterm angiographic and clinical follow-up-results.
\end{abstract}

MATERIALS AND METHODS: We performed a retrospective analysis of all ruptured and unruptured aneurysms treated with a WEB device (WEB Single-Layer and Single-Layer Sphere) between August 2014 and February 2017. Primary outcome measures included the feasibility of implantation and the angiographic outcome. Secondary outcome measures included the clinical outcome at discharge and procedural complications.

RESULTS: One hundred two aneurysms in 101 patients, including 37 (36.3\%) ruptured aneurysms, were treated with the WEB device. Implantation was successful in 98 (96.1\%) aneurysms. Additional devices (stents/coils) were necessary in 15.3\% (15/98) of aneurysms. Procedural complications occurred in 4.9\% (5/102). Of these, 4 were thromboembolic events and 1 was an intraprocedural rupture. Angiographic follow-up at 3 and 12 months was available for $79.6 \%(78 / 98)$ and $50.0 \%$ (49/98) of all aneurysms to date, respectively, showing a sufficient aneurysm occlusion in $80.7 \%$ (63/78) at 3 months and $77.6 \%(38 / 49)$ at 12 months. Delayed aneurysm ruptures have not been observed during the follow-up period to date.

CONCLUSIONS: The WEB device offers a safe and effective treatment option for broad-based intracranial aneurysms without the need for dual antiplatelet therapy.

ABBREVIATIONS: ASA = acetylsalicylic acid; WEB = Woven EndoBridge; DL = Dual-Layer; SL $=$ Single-Layer; SLS $=$ Single-Layer Sphere

E

endovascular occlusion of both ruptured and unruptured inCtracranial aneurysms has developed to a standard treatment with favorable results during the past decades. ${ }^{1-3}$ Standard coiling of wide-neck bifurcation aneurysms has a relevant risk of thromboembolic complications with lower occlusion rates. ${ }^{4}$ Several endovascular concepts address the problem of wide-neck aneurysms, whereas stent-assisted coiling and flow diversion represent the most popular techniques besides a growing number of innovative endovascular concepts. ${ }^{5,6}$

Received May 4, 2017; accepted after revision August 7.

From the Institut für Diagnostische und Interventionelle Radiologie, Neuroradiologie, Nuklearmedizin (J.P., W.W., S.F.), Knappschaftskrankenhaus Bochum-Langendreer, Universitätsklinik, Bochum, Germany; and Klinik für Diagnostische Radiologie und Neuroradiologie (A.B.), Klinikum Augsburg, Augsburg, Germany.

Please address correspondence to Sebastian Fischer, MD, Knappschaftskrankenhaus Bochum-Langendreer, Universitätsklinik, Institut für Diagnostische und Interventionelle Radiologie, Neuroradiologie, Nuklearmedizin, In der Schornau 23-25, 44892 Bochum, Germany; e-mail: sebif101@googlemail.com

http://dx.doi.org/10.3174/ajnr.A5413
Techniques that aim to reconstruct the parent artery with neointimal growth over the aneurysmal orifice require an implant inside the parent artery, with the imperative of using antiplatelet medications. Stent-assisted coiling or flow diversion is therefore limited to unruptured aneurysms in most cases. ${ }^{7}$ Piotin et al ${ }^{8}$ reported that stents were associated with increased morbidity compared with standard coiling. While extra-aneurysmal flow diverters have proved their effectiveness in sidewall aneurysms, the concept remains challenging in bifurcation aneurysms because 1 branch is covered by the device. Nevertheless, Yavuz et $\mathrm{al}^{9}$ presented a series of 25 MCA bifurcation aneurysms treated with the Pipeline Embolization Device (Covidien, Irvine, California).

The introduction of the Woven EndoBridge (WEB) aneurysm embolization system (Sequent Medical, Aliso Viejo, California) as a self-expanding intra-aneurysmal flow diverter in 2010 offered an innovative option for broad-based intracranial aneurysms without the need for concomitant dual antiplatelet therapy.

Here we report our experience with the WEB Single-Layer 
(SL) and Single-Layer Sphere (SLS) devices in the endovascular treatment of ruptured and nonruptured intracranial aneurysms.

\section{MATERIALS AND METHODS WEB Devices Used in This Series}

The WEB device is an intra-aneurysmal implant consisting of a selfexpanding nitinol braid. The device is electrothermally detachable and is introduced through microcatheters with diameters dependent on the size of the device. The initial version was introduced as the WEB Dual-Layer (DL) in 2010, with a second mesh placed inside the primary braid to achieve increased coverage at the neck region of the aneurysm. This version was replaced by the WEB SL and WEB SLS in 2013, which are devices with a single-layer mesh, whereas the SLS version has a more spheric shape, designed for the treatment of rounded aneurysms compared with the barrel-like shape of the SL version. The available diameters of the recent versions range from 4 (144 wires) to $11 \mathrm{~mm}$ (216 wires) in 1-mm increments, with lengths ranging from 3 to $7 \mathrm{~mm}$ for the SL version. The length of the SLS device is determined by its diameter and results from a subtraction of $1.6 \mathrm{~mm}$. Devices up to a diameter of $7 \mathrm{~mm}$ have been compatible with a 0.021 -inch microcatheter since 2015, whereas diameters of 8 and $9 \mathrm{~mm}$ need an 0.027-inch microcatheter, and the largest sizes of $10-11 \mathrm{~mm}$ require a 0.033 -inch microcatheter. ${ }^{6,10}$ The VIA Microcatheter (Sequent Medical) is designed for the delivery of the WEB device.

The aneurysms analyzed in the present study were exclusively treated with WEB SL and SLS versions.

\section{Inclusion and Exclusion Criteria}

Each case was discussed at an institutional neurovascular board, including neurosurgical, neurologic, and neurointerventional experts at the 2 participating neurointerventional centers. The decision for endovascular treatment was reached by consensus. The final endovascular treatment strategy was determined by the operator.

Criteria to use the WEB device were a wide neck and a fundus width between 3 and $10 \mathrm{~mm}$. Arguments in favor of endovascular treatment compared with neurosurgical clipping were an aneurysm location in the posterior circulation and an anticipated surgical difficulty. Saccular aneurysms with a maximum width below $3 \mathrm{~mm}$ or above $10 \mathrm{~mm}(+1 /-1$ rule described below), those with a dome-to-neck ratio of $<1$ (missing stability for the WEB device), and fusiform and extradural aneurysms were not considered.

All patients were informed of the planned treatment usually before admission but at least 1 day before the procedure, except those with an acute SAH. The clinical status of each patient with an unruptured aneurysm was graded by the modified Rankin Scale on admission, at discharge, and at each follow-up visit by a neurovascular team member. Patients with an acute SAH were graded by the Hunt and Hess scale initially. All clinical and radiographic data were analyzed in retrospect. Complications that resulted in a permanent clinical decline were defined as relevant and were analyzed separately. The study was approved by the local ethics committee.

\section{Endovascular Procedure and Device Selection}

Procedures were performed with the patient under general anesthesia by 4 experienced interventionalists. In elective procedures, a dual antiplatelet medication with acetylsalicylic acid (ASA) and clopidogrel was initiated at least 1 day before the procedure (500 $\mathrm{mg}$ of ASA and $600 \mathrm{mg}$ of clopidogrel followed by a daily dose of $100 \mathrm{mg}$ of ASA and $75 \mathrm{mg}$ of clopidogrel) to permit the possibility of stent-assisted coiling, if needed. The response to the antiplatelet medication was not routinely tested. Single antiplatelet therapy with $100 \mathrm{mg}$ of ASA daily was continued for at least 1 month. All procedures were performed with an initial intravenous bolus of heparin (5000 IU).

An $8 \mathrm{~F} / 6 \mathrm{~F}$ combination of guiding catheters or a $6 \mathrm{~F}$ catheter alone was introduced into the target artery. The aneurysm was visualized in an angulation without superimposition of surrounding branches.

Size selection of the WEB resulted from exact calibrated measurements of the aneurysm (width and height of the fundus, width of the neck) in 2 orthogonal projections based on a $3 \mathrm{D}$ rotational angiographic dataset. Because a stable position of the WEB inside the aneurysm results from a slight oversizing of the device, $1 \mathrm{~mm}$ was added to the average width of the aneurysms to assure good wall apposition of the device inside the aneurysm. The height of the selected device was therefore 1 $\mathrm{mm}$ lower than the average height of the aneurysm to adjust for the longitudinal increase caused by the horizontal compression $(+1 /-1$ rule $) .^{11}$

An appropriate VIA microcatheter was placed inside the aneurysmal fundus followed by the deployment of the WEB, which results from a combination of forward pushing of the device with simultaneous withdrawal of the microcatheter.

At this point in the procedure, the appropriate position of the WEB device was documented under fluoroscopy or an additional angiographic run including 3D angiography. In procedures with residual contrast filling between the device and the aneurysmal wall (radial flow), the WEB was withdrawn and a larger device was implanted. A slight extension of the mesh and the proximal detachment marker into the parent artery was tolerated if no evidence of flow compromise or thrombus formation occurred during an observational period of at least 10 minutes. The device was removed or a self-expanding stent was implanted to protect the parent artery in cases of distinct malposition. The stable position of the WEB was documented on a final angiographic run after detachment under continuous fluoroscopy.

\section{Follow-Up Schedule}

Angiographic follow-up examinations were scheduled at 3 and 12 months after treatment. The angiographic results were evaluated independently by 2 neuroradiologists on the basis of a 5-grade scale as described by Caroff et $\mathrm{al}^{12}: 1$, no residual flow in aneurysm/WEB; 2, opacification of the proximal recess of WEB; 3 , neck remnant; 4, residual flow inside the WEB; 5, aneurysm remnant. Grades 1 and 2 were considered complete occlusion. Grades 1-3 indicated a sufficient aneurysm occlusion.

\section{Statistical Analysis}

The statistical analysis of all variables was performed independently with Excel (Microsoft, Redmond, Washington). Continuous variables were described by median and range. Independent variables were characterized as percentages. 


\section{Ethical Standards and Patient Consent}

Wedeclare that all human and animal studies have been approved by the ethics committee of Ruhr Universität Bochum, Germany, and have therefore been performed in accordance with the ethical standards laid down in the 1964 Declaration of Helsinki and its later amendments. A separate informed consent from each patient before inclusion in this study was not required due to the design of the study.

\section{RESULTS}

\section{Patient Population}

Between August 2014 and February 2017, one hundred one patients (median age, 58.6 years; range, $28-89$ years) with 102 intracranial aneurysms were treated.

\section{Aneurysm Characteristics}

Of the 102 aneurysms treated in this series, 37 were acutely ruptured (maximum of 7 days from SAH to treatment), 60 were incidental findings, and 5 were remnants of previously coiled or clipped aneurysms. The median fundus width of all aneurysms

Table 1: Baseline patient $(n=101)$ characteristics

\begin{tabular}{lccc}
\hline \multicolumn{2}{c}{ Without Hemorrhage } & \multicolumn{2}{c}{ SAH } \\
\hline Total & $64(100 \%)$ & & $37(100 \%)$ \\
mRS 0 & $52(81.3 \%)$ & $\mathrm{HH}$ & $10(27.1 \%)$ \\
mRS 1 & $6(9.4 \%)$ & $\mathrm{HH} \mathrm{2}$ & $9(24.3 \%)$ \\
mRS 2 & $2(3.1 \%)$ & $\mathrm{HH} \mathrm{3}$ & $5(13.5 \%)$ \\
mRS 3 & $2(3.1 \%)$ & $\mathrm{HH} 4$ & $5(13.5 \%)$ \\
mRS 4 & $2(3.1 \%)$ & $\mathrm{HH} \mathrm{5}$ & $8(21.6 \%)$ \\
mRS 5 & $0(0.0 \%)$ & & \\
\hline
\end{tabular}

Note:- - H indicates Hunt and Hess.

Table 2: Baseline aneurysm $(n=102)$ characteristics

\begin{tabular}{lccc}
\hline \multicolumn{1}{c}{ Aneurysm } & No. (\%) & Unruptured & Ruptured \\
\hline Total & $102(100 \%)$ & $65(100 \%)$ & $37(100 \%)$ \\
Anterior circulation & $88(86.3 \%)$ & $60(92.3 \%)$ & $28(75.7 \%)$ \\
Posterior circulation & $14(13.7 \%)$ & $5(7.7 \%)$ & $9(24.3 \%)$ \\
AcomA & $33(32.4 \%)$ & $21(32.3 \%)$ & $12(32.4 \%)$ \\
MCA & $44(43.1 \%)$ & $34(52.3 \%)$ & $10(27.1 \%)$ \\
AchA & $1(1.0 \%)$ & $0(0.0 \%)$ & $1(2.7 \%)$ \\
ICA-T & $7(6.9 \%)$ & $5(7.7 \%)$ & $2(5.4 \%)$ \\
PcomA & $3(2.9 \%)$ & $0(0.0 \%)$ & $3(8.1 \%)$ \\
BA tip & $12(11.8 \%)$ & $4(6.2 \%)$ & $8(21.6 \%)$ \\
SCA & $2(1.9 \%)$ & $1(1.5 \%)$ & $1(2.7 \%)$ \\
\hline
\end{tabular}

Note:-AchA indicates anterior choroidal artery; AcomA, anterior communicating artery; BA, basilar artery; ICA-T, terminus of internal carotid artery; PcomA, posterior communicating artery; SCA, superior cerebellar artery.
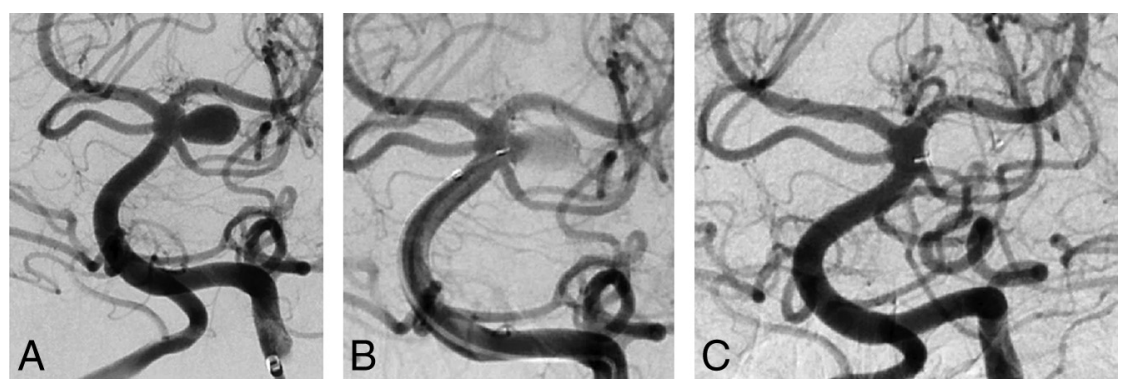

FIG 1. $A$, Incidental finding of an aneurysm of the origin of the superior cerebellar artery (anteroposterior view). B, Implantation of a WEB SL 7-4 without flow disturbance in the parent arteries (anteroposterior view). C, Three-month follow-up angiography with complete occlusion of the aneurysm and reconstruction of the neck area (anteroposterior view). was $6.0 \mathrm{~mm}$ (range, $4-10 \mathrm{~mm}$ ) with a median neck width of 4.6 $\mathrm{mm}$ (range, $4-7 \mathrm{~mm}$ ). Tables 1 and 2 summarize the locations and baseline characteristics.

\section{Procedural Results}

Implantation was successful in all except 4 aneurysms (3.9\%), which were excluded from the follow-up analysis. In 2 cases of MCA aneurysms, the WEB was withdrawn due to a flow deceleration in the MCA branch originating from the aneurysm base. Another MCA aneurysm was not accessible with the microcatheter because of a severe elongation of the ICA, and 1 anterior communicating artery aneurysm was in a very tight angulation to the parent artery. The treatment strategy was changed to stentassisted coiling in 3 procedures, and 1 aneurysm was finally clipped.

The procedure was completed with a WEB device only as intended in $83(81.4 \%)$ aneurysms (Fig 1), whereas in 7 (6.9\%), additional coils were necessary to completely fill the aneurysm. In another $8(7.8 \%)$ procedures, a self-expanding stent was implanted to guarantee a stable position of the WEB. This was combined with additional coiling in 1 aneurysm.

\section{Immediate and Follow-Up Angiographic Results}

In the Entire Series. A first follow-up angiography was available for 78/98 (79.6\%) aneurysms to date after a median of 3.5 months (range, 1.0-21.0 months), showing complete occlusion (grades 1 and 2) in $47 / 78(60.2 \%)$ and sufficient aneurysm occlusion (grades $1-3$ ) in $63 / 78(80.7 \%)$. Of the remaining 20 patients, 9 died as consequence of their SAH, 9 were lost to follow-up, 1 died of causes unrelated to the treated aneurysm, and 1 died of causes related to the procedure (see below). A second follow-up angiography was performed in 49/98 (50.0\%) after a median of 8.6 months (range, 2.0-20.0 months), showing complete occlusion in $29 / 49$ (59.2\%) and sufficient occlusion in $38 / 49$ aneurysms $(77.6 \%)$. Retreatment has been necessary in 10 aneurysms to date due to a regrowth of the aneurysms or a clustering of the WEB.

In Unruptured Aneurysms. At least 1 follow-up angiography was performed in $91.8 \%(56 / 61)$ of all unruptured aneurysms, showing complete occlusion in $60.8 \%(34 / 56)$ and sufficient occlusion in $82.2 \%$ (46/56). Thirty-seven of the 61 aneurysms $(60.7 \%)$ were evaluated in a second angiography to date. Of those, 59.4\% (22/37) were completely occluded and $78.3 \%$ (29/37) showed sufficient occlusion. 
Table 3: Immediate and follow-up results of ruptured aneurysms ${ }^{a}$

\begin{tabular}{lccc}
\hline & Immediate & $\begin{array}{c}\text { 3-Month } \\
\text { Follow-Up }\end{array}$ & $\begin{array}{c}\text { 12-Month } \\
\text { Follow-Up }\end{array}$ \\
\hline $\begin{array}{l}\text { Total } \\
\text { Grade }\end{array}$ & $37(100 \%)$ & $22(59.5 \%)$ & $12(32.4 \%)$ \\
1 & & & \\
2 & $5(13.5 \%)$ & $11(50.0 \%)$ & $6(50.0 \%)$ \\
3 & $1(2.7 \%)$ & $2(9.1 \%)$ & $1(8.3 \%)$ \\
4 & $2(5.4 \%)$ & $4(18.2 \%)$ & $2(16.7 \%)$ \\
5 & $29(78.4 \%)$ & $2(9.1 \%)$ & $1(8.3 \%)$ \\
Complete occlusion & $0(0.0 \%)$ & $3(13.6 \%)$ & $2(16.7 \%)$ \\
$\quad$ (grades 1 and 2) & & $13(59.1 \%)$ & $7(58.3 \%)$ \\
Sufficient occlusion & & & \\
$\quad$ (grades 1-3) & & $17(77.3 \%)$ & $9(75.0 \%)$ \\
\hline
\end{tabular}

${ }^{a} 1$ indicates no residual flow in aneurysm/WEB; 2 , opacification of the proximal recess of the WEB; 3 , neck remnant; 4 , residual flow inside the WEB; 5 , aneurysm remnant.

Table 4: Immediate and follow-up results of unruptured aneurysms $^{\mathrm{a}}$

\begin{tabular}{lccc}
\hline & Immediate & $\begin{array}{c}\text { 3-Month } \\
\text { Follow-Up }\end{array}$ & $\begin{array}{c}\text { 12-Month } \\
\text { Follow-Up }\end{array}$ \\
\hline Total & $61(100 \%)$ & $56(91.8 \%)$ & $37(60.7 \%)$ \\
Grade & & & \\
1 & $3(4.9 \%)$ & $22(39.4 \%)$ & $15(40.5 \%)$ \\
2 & $5(8.2 \%)$ & $12(21.4 \%)$ & $7(18.9 \%)$ \\
3 & $0(0.0 \%)$ & $12(21.4 \%)$ & $7(18.9 \%)$ \\
4 & $53(86.9 \%)$ & $5(8.9 \%)$ & $3(8.2 \%)$ \\
5 & $0(0.0 \%)$ & $5(8.9 \%)$ & $5(13.5 \%)$ \\
Complete occlusion & & $34(60.8 \%)$ & $22(59.4 \%)$ \\
$\quad \quad$ (grades 1 and 2) & & & \\
Sufficient occlusion & & $46(82.2 \%)$ & $29(78.3 \%)$ \\
$\quad$ (grades 1-3) & & & \\
\hline
\end{tabular}

a 1 indicates no residual flow in aneurysm/WEB; 2 , opacification of the proximal recess of the WEB; 3 , neck remnant; 4, residual flow inside the WEB; 5 , aneurysm remnant.

Table 5: Immediate and follow-up results of ruptured and unruptured aneurysms ${ }^{a}$

\begin{tabular}{lccc}
\hline & Immediate & $\begin{array}{c}\text { 3-Month } \\
\text { Follow-Up }\end{array}$ & $\begin{array}{c}\text { 12-Month } \\
\text { Follow-Up }\end{array}$ \\
\hline $\begin{array}{l}\text { Total } \\
\text { Grade }\end{array}$ & $98(100 \%)$ & $78(79.6 \%)$ & $49(50.0 \%)$ \\
1 & & & \\
2 & $8(8.2 \%)$ & $33(42.3 \%)$ & $21(42.9 \%)$ \\
3 & $6(6.1 \%)$ & $14(17.9 \%)$ & $8(16.3 \%)$ \\
4 & $2(2.0 \%)$ & $16(20.5 \%)$ & $9(18.4 \%)$ \\
5 & $82(83.7 \%)$ & $7(9.0 \%)$ & $4(8.1 \%)$ \\
Complete occlusion & $0(0.0 \%)$ & $8(10.3 \%)$ & $7(14.3 \%)$ \\
$\quad$ (grades 1 and 2) & & $47(60.2 \%)$ & $29(59.2 \%)$ \\
Sufficient occlusion & & & \\
$\quad$ (grades 1-3) & & $63(80.7 \%)$ & $38(77.6 \%)$ \\
\hline
\end{tabular}

${ }^{a} 1$ indicates no residual flow in aneurysm/WEB; 2 , opacification of the proximal recess of the WEB; 3 , neck remnant; 4, residual flow inside the WEB; 5 , aneurysm remnant.

\section{Peri- and Early Postprocedural Clinically Relevant Complications}

Clinically relevant complications occurred in 5 patients $(4.9 \%)$, resulting in morbidity and mortality rates of $4.0 \%(4 / 101$ patients) and $1.0 \%$ (1/101 patients), respectively.

Of those, 4 were thromboembolic compared with 1 intraprocedural rupture. One patient with an incidental middle cerebral artery aneurysm (M1 segment) and the temporal branch arising close to the aneurysm neck was treated with a WEB SL $(6 \times 3)$ device. The proximal part of the device slightly extended into the parent artery without evidence of thrombus formation. Nevertheless, the operator decided to place a self-expanding stent (LVIS;
MicroVention, Tustin, California) to stabilize the device. The procedure was finished without flow compromise in the parent artery or the temporal branch. Approximately 30 minutes later, the patient developed a hemiparesis of the left arm. Angiography revealed a thrombotic occlusion of the temporal branch with no flow compromise in the M1 segment. The aneurysm showed complete occlusion. After an interdisciplinary discussion, $20 \mathrm{~mL}$ of alteplase (Actilyse; Boehringer Ingelheim Pharma, Germany) was infused for 30 minutes with a microcatheter placed in the proximal M1 segment, which resulted in a complete recanalization of the branch. The decision to use alteplase was derived by consensus, even though a recently published meta-analysis showed lower morbidity rates with glycoprotein IIb/IIIa inhibitors. ${ }^{13}$ The paresis of the left arm remained unchanged (mRS 3 ). MR imaging performed 2 days later revealed an ischemic lesion in the right MCA territory.

Another 89-year-old patient with a ruptured ICA posterior communicating artery aneurysm was treated with a WEB SL $(5 \times 3)$ without extension into the ICA; 30 minutes after the procedure, the patient showed a left-sided hemiplegia. Angiography revealed a thrombotic occlusion of the terminal ICA, treated by an intra-arterial infusion of $33 \mathrm{~mL}$ of tirofiban without complete resolution of the thrombus after an observational period of 120 minutes. A mechanical thrombectomy with a pREset system (phenox, Bochum, Germany) resulted in complete recanalization. Another 20 minutes later, angiography showed a recurrent thrombus formation at the aneurysm orifice, which was successfully treated with a self-expanding stent (Neuroform Atlas; Stryker Neurovascular, Kalamazoo, Michigan). The patient was placed on ticagrelor thereafter. The procedure was terminated without evidence of further thrombus formation or an intracranial hemorrhage. The hemiplegia remained. One day later the patient declined finally to a comatose status. CT revealed a complete infarction of the right MCA and anterior cerebral artery territory with massive swelling. A day later, the patient died.

The remaining thromboembolic complications both occurred in incidental aneurysms (MCA and anterior cerebral artery) treated with additional self-expanding stents (LVIS). Both patients showed clinically relevant strokes on postprocedural CT scans without evidence of in-stent thrombosis, probably related to distal emboli caused by the stent implantation resulting in an mRS grade of 3 .

In 1 case of a ruptured ICA aneurysm, a rerupture occurred with a VIA 27 microcatheter. The microcatheter was left in place followed by the implantation of a WEB $($ SL $8 \times 6)$ partially outside the aneurysm, which resulted in prompt hemostasis. The remaining aneurysm was then occluded by stent-assisted coiling (Neuroform Atlas). A left-sided hemiparesis resolved completely (Fig 2A-D).

\section{Delayed Complications}

Neither delayed aneurysm ruptures nor thromboembolic complications have been observed during the follow-up period to date. 

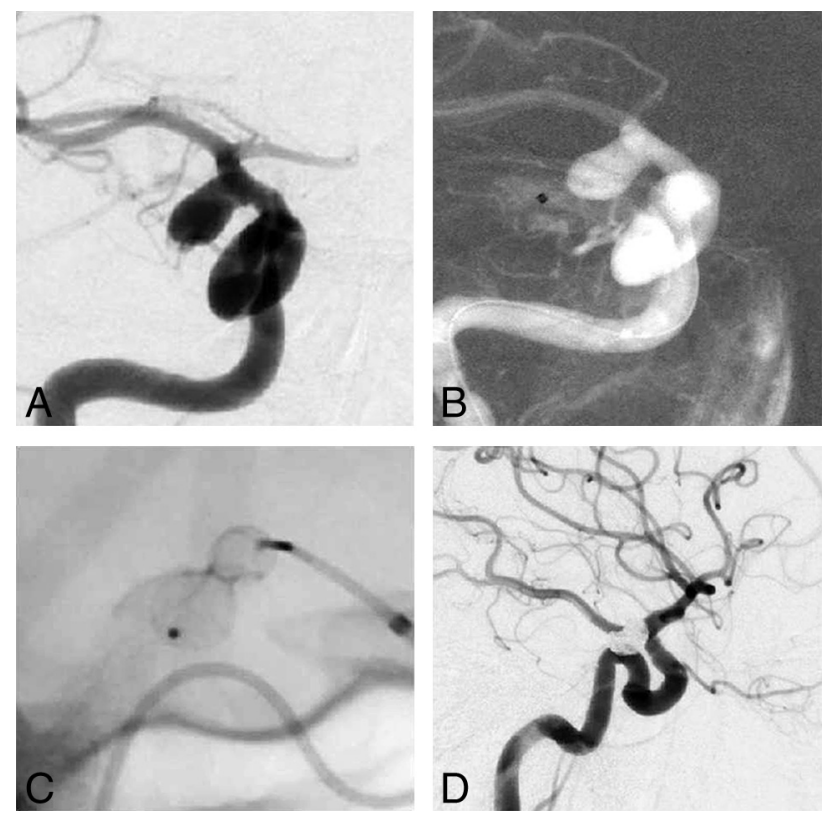

FIG 2. A, Acutely ruptured broad-based ICA posterior communicating artery aneurysm (anteroposterior view). B, Catheterization followed by aneurysm rupture; VIA 27 microcatheter outside the aneurysm (roadmap in the anteroposterior view). C, Placement of a WEB SL 8-6 partly outside the aneurysm showing a constriction of the WEB at the point of rupture (single image without subtraction). $D$, Final complete occlusion of the aneurysm by stent-assisted coiling (lateral view).

\section{DISCUSSION}

In this retrospective study, we analyzed the angiographic and clinical results in the treatment of both ruptured and unruptured intracranial aneurysms with the WEB device.

The technical success rate of $96.1 \%$ and the rate of thromboembolic complications (3.9\%) are comparable with those reported in the literature. ${ }^{14-21}$

The main drawback of stent-assisted coiling is the need for dual antiplatelet medication. Nishido et $\mathrm{al}^{22}$ compared the clinical and angiographic results of 1815 saccular aneurysms treated with stents $(n=299)$ with those treated without $(n=1492)$. They found a lower rate of recurrence in the group treated with stents, while the rate of complications was significantly higher $(9.4 \%$ versus $5.6 \%$ ). Adeeb et $\mathrm{al}^{23}$ in their series of 74 aneurysms treated with a single stent, observed an immediate complete occlusion rate of $52.7 \%$ with an improvement to $70.3 \%$ during the follow-up period of 15.2 months. These results are comparable with those in our series.

Our results are in line with those of previously published series: Pierot et $\mathrm{al}^{17}$ presented the results of 55 aneurysms treated at 10 neurointerventional centers. They found a 1-year complete occlusion rate of $54.0 \%$ and a neck remnant in $26.0 \%$. The rate of ruptured aneurysms in this series was $7.3 \%$ $(n=4)$. The mortality rate at 1 year was $2.0 \%$. The results of 2 good clinical practice studies with the WEB device (WEBCAST and French Observatory) are analyzed in another publication of Pierot et al. ${ }^{24}$ In the cumulated series of 114 aneurysms treated with the WEB DL $(n=82)$ and the WEB SL/SLS $(n=$ 32), 10 aneurysms were ruptured. The rate of thromboembolic events was significantly higher in the group of 16 patients with- out a prophylactic antiplatelet medication (56.3\%) compared with those with 1 antiplatelet agent 12\% (6/50). These data might diminish the advantage of the WEB device against stentassisted coiling and indicate the need for at least 1 antiplatelet agent in elective procedures, but $71.9 \%$ of all aneurysms in this series were treated with the WEB DL version, which might be of a higher thrombogenicity, probability due to the doublelayer surface at the aneurysm orifice.

A dual antiplatelet therapy was initiated in all elective patients of our series. The medication with ASA, $100 \mathrm{mg}$, was continued for at least 4 weeks as described above. In patients with an acute $\mathrm{SAH}$, the procedure was performed without a periprocedural antiplatelet medication followed by a monotherapy with $100 \mathrm{mg}$ of ASA for at least 4 weeks.

Fiorella et al ${ }^{18}$ presented the 30 -day safety results of the WEB Intrasaccular Therapy (WEB-IT) study. They recommended a monotherapy with $100 \mathrm{mg}$ of ASA before the procedure in less complex cases, while in broad-based anatomies, they initiated a dual antiplatelet therapy continued for 90 days if a protrusion of the WEB into the parent artery occurred. They observed 7 minor ischemic strokes during the follow-up period, with 2 of them resulting in an mRS of 1 . Adjunctive devices were used in 7 aneurysms (2 stents, 7 balloons). Treatment with the WEB device failed in 2 patients. The mortality rate in the entire series is $0 \%$ to date.

\section{Technical Aspects}

As described above, we encountered 1 intraprocedural rupture. Van Rooij et $\mathrm{al}^{21}$ in their series of 32 acutely ruptured aneurysms treated with the WEB device observed no procedural perforation. However, acutely ruptured aneurysms are generally known for their higher risk of procedural perforations. ${ }^{16,25}$ Deployment of the WEB should be performed without contact of the device to the aneurysm wall until two-thirds of the mesh is unfolded. At this point, the device engages a centered position inside the aneurysm with invagination of its tip. The possibility of implanting a WEB device with a 0.017 -inch microcatheter (not used in our study) might ease the procedure.

\section{Thromboembolic Complications}

The rate of thromboembolic complications in our cohort is similar to that in other studies. Pierot et $\mathrm{al}^{17}$ observed thromboembolic events in 9 of $51(17.7 \%)$ patients. They found a trend toward lower thromboembolic complications with the WEB SL/SLS compared with the WEB DL version, which was not used in our series. Most interesting, 3 of the thromboembolic complications in our series occurred with self-expanding stents. This might indicate the positive relation between adjunctive devices and thromboembolic complications.

The importance of a meticulous case and device selection becomes clear against these findings because the need for additional devices will be lower with an exact fitting between the aneurysm and the WEB device.

Lawson et $\mathrm{al}^{15}$ in their series of 22 aneurysms treated with the WEB device observed 1 symptomatic ischemic event. The WEB used is this case was oversized. These findings are similar to those of Caroff et al, ${ }^{20}$ who found 2 strokes in their series due to the use 
of oversized WEB devices. The authors concluded that undersizing can lead to recurrence and residual aneurysm, while excessive oversizing may promote clot formation and thromboembolism.

\section{Follow-Up Results}

While standard coiling procedures result in an absence of contrast media, aneurysms treated with the WEB frequently show a remaining perfusion after implantation. This impedes a direct comparison between the techniques and raises the question of sufficient protection from further ruptures. We did not observe any cases of aneurysm rupture during the follow-up period either in the incidental or ruptured group.

We classified the angiographic results on the basis of a 5-point scale as suggested by Caroff et al. ${ }^{12}$ This, in contrast to a 3-point scale, allows differentiation between a typical aneurysm remnant, which might require retreatment in the future, and an opacification inside the mesh of the WEB, which might result in a contemporary intra-aneurysmal thrombosis without additional treatment. ${ }^{26}$ Mine et al, ${ }^{27}$ in their recently published series of 49 aneurysms treated with the WEB device, demonstrated that a small proximal recess related to the device should not be considered a remnant and remains stable with time. According to these findings, the rate of complete aneurysm occlusion at 3 and 12 months is $60.2 \%(47 / 78)$ and $59.2 \%$ (29/49), respectively, in our series.

Our results with a sufficient occlusion of almost $80 \%$ are comparable with those in previously published series. We have observed no major difference between ruptured and unruptured aneurysms during the follow-up period to date, though the comparability of the 2 groups is restricted due to the different sample sizes.

\section{Advantages and Disadvantages in Ruptured Aneurysms}

The main advantage is the possibility of treating ruptured aneurysms without periprocedural antiplatelet medication. Another major benefit consists of the reduced overall procedure time. An analysis of the WEB-IT study showed that one-third of all procedures were completed in $<20$ minutes. ${ }^{18}$ This is in line with our experience, though we did not analyze the procedure times. We observed 1 intraprocedural rupture that was rapidly stopped by the implantation of the WEB, similar to the findings in the WEB-IT cohort with 2 hemorrhages. The capability of the WEB to induce hemostasis promptly is another advantage. The limitation in size and the learning curve with this new device might be considered a temporary drawback compared with standard concepts.

\section{Limitations of the Study}

Our study has several limitations. The retrospective character of the study with 2 different centers might cause inhomogeneity of the data. Factors such as the number of attempts before implantation of the device, duration of the procedure, and the learning curve were not considered. The limited number of treated aneurysms and follow-up data impedes a separate analysis of ruptured and unruptured aneurysms. The angiographic results were classified without an independent assessment. ${ }^{28}$

\section{CONCLUSIONS}

The WEB device offers a safe and effective treatment option for broad-based aneurysms, independent of the status of rupture, without the need for a dual antiplatelet therapy. Proper device selection appears to be a key factor in minimizing the risk of thromboembolic complications and may increase the rate of sufficient aneurysm occlusion. Further studies with longer follow-up data will prove the significance of the presented therapy.

Disclosures: Ansgar Berlis—RELATED: Consulting Fee or Honorarium: Sequent Medical, MicroVention, Comments: proctor contract; UNRELATED: Consultancy: Stryker, Medtronic, Comments: proctor contract; Payment for Lectures Including Service on Speakers Bureaus: Penumbra. Werner Weber-RELATED: Consultancy: R\&D team of Sequent, MicroVention; Payment for Lectures Including Service on Speakers Bureaus: MicroVention; Other: proctoring the WEB device in Europe and Germany. * Sebastian Fischer-UNRELATED: Board Membership: Codman Neurovascular, Comments: Advisory Board; Payment for Lectures Including Service on Speakers Bureaus: Sequent Medical, Comments: speaking honorarium. *Money paid to the institution.

\section{REFERENCES}

1. Sorenson T, Lanzino G. Trials and tribulations: an evidence-based approach to aneurysm treatment. J Neurosurg Sci 2016;60:22-26 Medline

2. Falk Delgado A, Andersson T, Falk Delgado A. Clinical outcome after surgical clipping or endovascular coiling for cerebral aneurysms: a pragmatic meta-analysis of randomized and non-randomized trials with short- and long-term follow-up. J Neurointerv Surg 2017;9: 264-77 CrossRef Medline

3. Henkes H, Fischer S, Weber W, et al. Endovascular coil occlusion of 1811 intracranial aneurysms: early angiographic and clinical results. Neurosurgery 2004;54:268-80; discussion 280-85 CrossRef Medline

4. Zhao B, Yin R, Lanzino G, et al. Endovascular coiling of wide-neck and wide-neck bifurcation aneurysms: a systematic review and meta-analysis. AJNR Am J Neuroradiol 2016;37:1700-05 CrossRef Medline

5. Pierot L, Biondi A. Endovascular techniques for the management of wide-neck intracaranial bifurcation aneurysms: a critical review of the literature. J Neuroradiol 2016;43:167-75 CrossRef Medline

6. Henkes H, Weber W. The past, present and future of endovascular aneurysm treatment. Clin Neuroradiol 2015;25(suppl 2):317-22 CrossRef Medline

7. Zhao B, Tan X, Yang H, et al. Stent-assisted coiling versus coiling alone of poor-grade ruptured intracranial aneurysms: a multicenter study. J Neurointervent Surg 2017;9:165-68 CrossRef Medline

8. Piotin M, Blanc R, Spelle L, et al. Stent-assisted coiling of intracranial aneurysms: clinical and angiographic results in 216 consecutive aneurysms. Stroke 2010;41:110-15 CrossRef Medline

9. Yavuz K, Geyik S, Saatci I, et al. Endovascular treatment of middle cerebral artery aneurysms with flow modification with the use of the Pipeline embolization device. AJNR Am J Neuroradiol 2014;35: 529-35 CrossRef Medline

10. Armoiry X, Turjman F, Hartmann DJ, et al. Endovascular treatment of intracranial aneurysms with the WEB device: a systematic review of clinical outcomes. AJNR Am J Neuroradiol 2016;37:868-72 CrossRef Medline

11. Lescher S, du Mensil de Rochemont R, Berkefeld J. Woven Endobridge (WEB) device for endovascular treatment of complex unruptured aneurysms: a single center experience. Neuroradiology 2016;58:883-90 CrossRef Medline

12. Caroff J, Mihalea C, Klisch C, et al. Single-layer WEBs: intrasaccular flow disrupters for aneurysm treatment-feasibility results from a European study. AJNR Am J Neuroradiol 2015;36:1942-46 CrossRef Medline

13. Brinjikji W, Morales-Valero SF, Murad MH, et al. Rescue treatment 
of thromboembolic complications during endovascular treatment of cerebral aneurysms: a meta-analysis. AJNR Am J Neuroradiol 2015;36:121-25 CrossRef Medline

14. Pierot L, Costalat V, Moret J, et al. Safety and efficacy of aneurysm treatment with WEB: results of the WEBCAST study. J Neurosurg 2016;214:1250-56 CrossRef Medline

15. Lawson A, Goddard T, Ross S, et al. Endovascular treatment of cerebral aneurysms using the Woven Endo Bridge technique in a single center: preliminary results. J Neurosurg 2017;126:17-28 CrossRef Medline

16. Asnafi S, Rouchaud A, Pierot L, et al. Efficacy and safety of the Woven EndoBridge (WEB) device for the treatment of intracranial aneurysms: a systematic review and meta-analysis. AJNR Am J Neuroradiol 2016;37:2287-92 CrossRef Medline

17. Pierot L, Gubucz I, Buhk JH, et al. Safety and efficacy of aneurysm treatment with the WEB: results of the WEBCAST 2 study. AJNR Am J Neuroradiol 2017;38:1151-55 CrossRef Medline

18. Fiorella D, Molineux A, Coon A, et al. Demographic, procedural and 30-day safety results from the WEB Intra-saccular Therapy Study (WEB-IT). J Neurointerv Surg 2017 Jan 17. [Epub ahead of print] CrossRef Medline

19. Clajus $C$, Strasilla C, Fiebig T, et al. Initial and mid-term results from 108 consecutive patients with cerebral aneurysms treated with the WEB device. J Neurointerv Surg 2017;9:411-47 CrossRef Medline

20. Caroff J, Mihaela C, Dargento F, et al. Woven Endobridge (WEB) device for endovascular treatment of ruptured intracranial wideneck aneurysms: a single center experience. Neuroradiology 2014;56: 755-61 CrossRef Medline

21. van Rooj WJ, Peluso JP, Bechan RS, et al. WEB treatment of ruptured intracranial aneurysms. AJNR Am J Neuroradiol 2016;37:1679-83 CrossRef Medline
22. Nishido H, Piotin M, Bartolini B, et al. Analysis of complications and recurrences of aneurysm coiling with special emphasis on the stent-assisted technique. AJNR Am J Neuroradiol 2014;35: 339-44 CrossRef Medline

23. Adeeb N, Grissenauer C, Patel A, et al. The use of single stent-assisted coiling in treatment of bifurcation aneurysms: a multicenter cohort study with proposal of a scoring system to predict complete occlusion. Neurosurgery 2017 Jun 8. [Epub ahead of print] CrossRef Medline

24. Pierot L, Spelle L, Molyneux A, et al. Clinical and anatomical follow-up in patients with aneurysms treated with the WEB device: 1-year follow-up report in the cumulated population of 2 prospective, multicenter series (WEBCAST and French Observatory). Neurosurgery 2016;78:133-41 CrossRef Medline

25. Orrù E, Roccatagliata L, Cester G, et al. Complications of endovascular treatment of cerebral aneurysms. Eur J Radiol 2013;82: 1653-58 CrossRef Medline

26. Fiorella D, Arthur A, Byrne J, et al. Interobserver variability in the assessment of aneurysm occlusion with the WEB aneurysm embolization system. J Neurointerv Surg 2015;7:591-95 CrossRef Medline

27. Mine B, Goutte A, Brisbois D, et al. Endovascular treatment of intracranial aneurysms with the Woven EndoBridge device: mid term and long term results. J Neurointerv Surg 2017 Feb 20. [Epub ahead of print] CrossRef Medline

28. Rezek I, Mousan G, Wang Z, et al. Effect of core laboratory and multiple reader interpretation of angiographic images on follow-up outcomes of coiled cerebral aneurysms: a systematic review and meta-analysis. AJNR Am J Neuroradiol 2013;34:1380-84 CrossRef Medline 